\title{
Acute toxicity of refined wild apricot oil in rats
}

\author{
Xingjun Miao ${ }^{\mathrm{a}}$, Zhong Zhao ${ }^{\mathrm{a}, \mathrm{b}, *}$, Hongjiao $\mathrm{Li}^{\mathrm{a}}$, Ming $\mathrm{Li}^{\mathrm{a}}$, Hailan $\mathrm{Zhu}^{\mathrm{a}}$ \\ ${ }^{\text {a }}$ College of Forestry, Northwest A\&F University, Yangling Shaanxi 712100 China \\ b Key Laboratory of Environment and Ecology in Western China of Ministry of Education, \\ Northwest A\&F University, Yangling Shaanxi 712100 China \\ *Corresponding author, e-mail: zhaozh@nwsuaf.edu.cn
}

Received 10 Oct 2013

Accepted 11 Oct 2014

\begin{abstract}
Wild apricot is distributed widely in China, and its kernel has been used as a raw material for oils and proteins. Although wild apricot oil is a rich source of unsaturated fatty acids, there are few reported findings on the toxicological aspects of pressed wild apricot oil. Thus an acute toxicity study was carried out with a refined wild apricot oil in albino Sprague-Dawley rats to assess its suitability as edible oil. We included $2.25 \mathrm{mg}$ amygdalin/ml in refined apricot oil and used the maximum tolerated dose test to evaluate the acute toxicity of the refined apricot oil. It did not result in any kind of abnormal behaviour in rats. No mortality was observed during 17 days in male rats or 15 days in female rats after treatment.
\end{abstract}

KEYWORDS: pressed oil, amygdalin, maximum tolerated dose

\section{INTRODUCTION}

Wild apricot kernels are dry mature seeds of Armeniaca sibirica L. (Siberian apricot) and A. vulgaris Lam. (common apricot) which are important species in the mountainous areas of northern China. The fruit of the wild apricot variety is nearly round in shape and has a smaller diameter than the cultivated variety. It is not palatable as it contains high acid and low sugar, whereas the cultivated variety is edible and used as a table fruit. Apricot kernels are important raw materials for the production of various products including oils and proteins. About $40-56 \mathrm{~g}$ of oil is present in $100 \mathrm{~g}$ of wild apricot kernel ${ }^{1}$. Apricot pits have been widely used in Chinese traditional medicine to treat asthma, aplastic anaemia, and tumours ${ }^{2}$. They can also be used as lubricants, cosmetics, and surfactants $^{3}$. Recently, researchers have examined the use of the wild apricot oil in many areas ${ }^{1,3,4}$. Although most of these studies suggest that the wild apricot oil is suitable for human consumption, they have found that wild apricot oil also contains up to $8 \%$ amygdalin ${ }^{5,6}$. From our production experience and detection, amygdalin or $\mathrm{HCN}$ inevitably enters the apricot oil during the cold pressing process ${ }^{7}$. Both amygdalin and $\mathrm{HCN}$ can cause acute intoxication and chronic syndromes of the human central nervous system. The presence of these toxic substances presents a challenge to the usage of kernel-derived products for human or animal consumption ${ }^{5}$. As few findings reports the toxicological properties of wild apricot oil, we used albino Sprague-Dawley (SD) rats to assess its suitability as edible oil.

\section{MATERIALS AND METHODS}

Wild apricot pits were obtained from market in Zhenyuan county, Gansu province. The pits were decorticated and the kernels obtained powdered and then extracted with a hot and cold dual-use screw presser (Zhengzhou Penguins grain and oil machinery co. Ltd, Henan province, Machine model: 6YL-800 $\mathrm{RL})$. The obtained yellow crude oil with a faint odour was then refined using water and centrifugation to reduce the cyanide content.

D-Amygdalin (D-mandelonitrile $\beta$-D-glucosido6- $\beta$-D-glucoside) was purchased from Sigma Chemistry Co. Ltd, Germany.

\section{Experimental animals}

Specific pathogen-free SD rats were obtained from Experimental Animals Centre in College of medicine of Xi'an Jiaotong University. All rats were divided into two groups according to sex.

\section{Acute toxicity in rats}

The test of maximum tolerated dose was used to evaluate the acute toxicity of refined wild apricot oil added amygdalin ${ }^{8}$. Rats used for the study were bred and maintained in-house. They were housed in plastic cages (10 animals per cage, segregated by sex) under the same conditions.

\section{Experimental procedure}

The rats were given food and water ad libitum. The animal room temperature was set within the range of 
$23 \pm 3{ }^{\circ} \mathrm{C}$ and relative humidity in the range of $40-$ $70 \%$. The test substance was administered by oral gavage using a blunt needle and syringe adapted for the purpose ${ }^{9}$. We used 20 rats $(10$ male and 10 female, weight between 180 and $220 \mathrm{~g}$ ). Food or water was withheld for $1 \mathrm{~h}$ after drug administration. Rats were closely observed during the initial $4 \mathrm{~h}$ after the administration, and then once daily during the following days. Gross morphological, physiological, behavioural changes, and mortality were closely observed for 14 days. The following behavioural changes were closely observed: hyperactivity, ataxia, tremors, convulsions, salivation, diarrhoea, lethargy, sleep, and coma ${ }^{10-12}$. Then the rats were allowed to access standard rodent pellet diet (provided by Xi'an Jiaotong University) for 2 weeks after gavage. Body weights and food consumption were recorded daily.

At the time of autopsy, blood was collected from the rat femoral vein while the animals were under chloral hydrate anaesthesia (10\%, ip). Blood from each animal was collected in a glass vial containing EDTA-K2 anticoagulant for haematology. Blood routine examination was determined by STAC Cell Analyser CA-500. The blood parameters measured included: red blood cell count (RBC), haematocrit (HCT), mean corpuscular volume (MCV), red cell distribution width (RDW), white blood cell count (WBC), lymphocytes (LYM), mononuclear cells (MON), neutrophil granulocytes (GRA), platelet count (PLT), thrombocytocrit (PCT), mean platelet volume (MPV), platelet distribution width (PDW), and haemoglobin $(\mathrm{Hb})^{13}$. The organ such as heart, liver, spleen, lungs, kidney and thymus were quickly removed and weighed individually after cleaned in normal saline and dried on filter paper ${ }^{14}$.

\section{RESULTS}

\section{The amygdalin content of test substance}

Cyanide contents of refined apricot oil were determined by isonicotinic acid/barbituric acid spectrophotometry ${ }^{7}$. In this study, the cyanide content of refined apricot oil was $0.11 \mathrm{mg} \mathrm{HCN} / \mathrm{kg}$, equivalent to $1.67 \mathrm{mg}$ amygdalin $/ \mathrm{kg}$ (density of oil is $0.9 \mathrm{~g} / \mathrm{ml}$ ). According to previous studies, the $\mathrm{LD}_{50}$ of amygdalin was about 522 or $880 \mathrm{mg} / \mathrm{kg} \mathrm{bw}^{9,15}$, and $\mathrm{LD}_{10}$ was about $250 \mathrm{mg} / \mathrm{kg} \mathrm{bw}^{15}$. Assuming that the poisoning effect follows a linear relationship, we calculated $\mathrm{LD}_{0}=250-\frac{1}{4}(522-250) \approx 180 \mathrm{mg} / \mathrm{kg}$ bw. Since the intragastric administration volume was $4.0 \mathrm{ml} / 200 \mathrm{~g}$ $\mathrm{bw}^{8}$, so the test substance dose was about $9 \mathrm{mg}$ amygdalin/ml. Finally, we chose $2.25 \mathrm{mg}$ amygdalin $/ \mathrm{ml}$ as the test substance concentration, because it had a

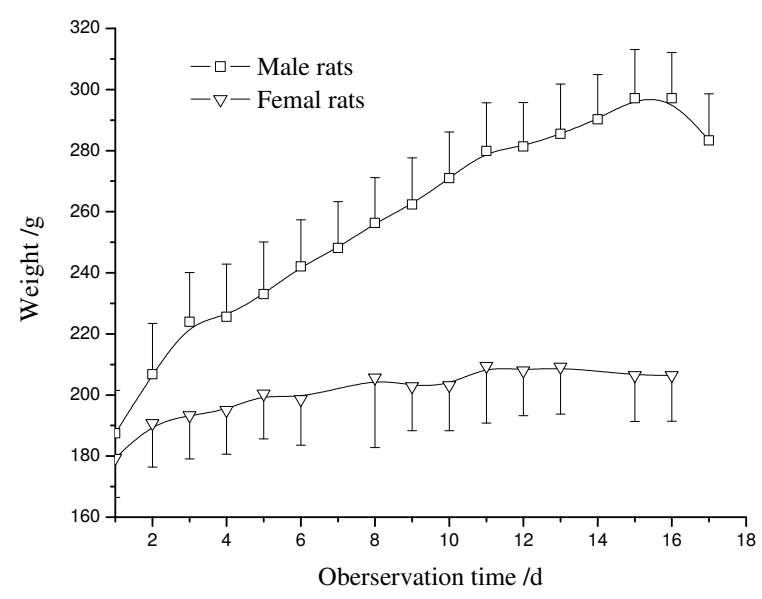

Fig. 1 Rats weight changes after oral administration.

better uniformity than the estimated dosage.

All rats had similar initial weight. After oral administration, male rats grew rapidly while female rats grew slowly (Fig. 1). Similarly, water and food intake of male rats were higher than that of the female rats (Fig. 2).

Rats were sacrificed and dissected for anatomical studies after anaesthesia. There were no obvious abnormalities to the organ and tissue, i.e., heart, liver, spleen, lungs, kidney, thymus, and with a normal organ relative weight for all the rats (Table 1). Also, the blood parameters were within a normal range for both male and female rats (Table 2).

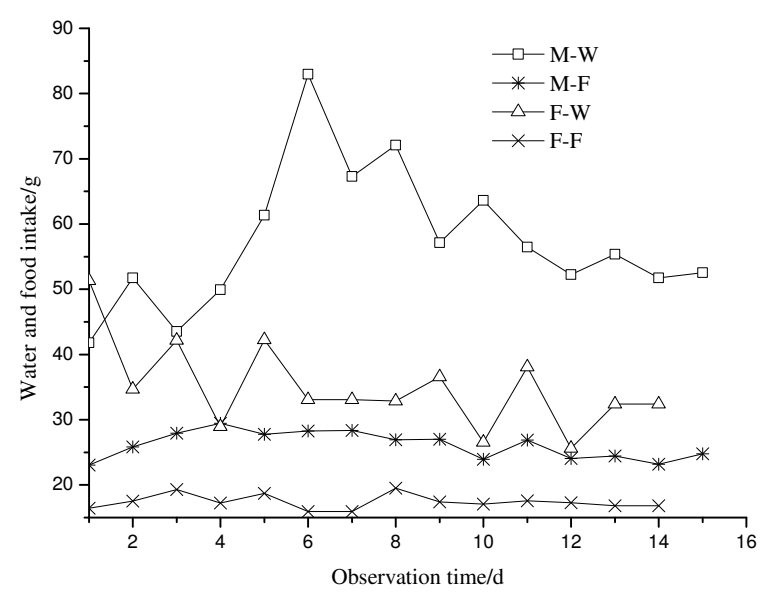

Fig. 2 Water and food intake after oral administration M-W: male rats water consumption, M-F: male rats food consumption, F-W: female rats water consumption, F-F: female rats food consumption. 
Table 1 Organ relative body weight of SD rats (g/100 g).

\begin{tabular}{lcccccc}
\hline Sex & Heart & Liver & Spleen & Lungs & Kidney & Thymus \\
\hline Male & $0.34 \pm 0.04$ & $2.93 \pm 0.16$ & $0.21 \pm 0.04$ & $0.61 \pm 0.11$ & $0.83 \pm 0.13$ & $0.19 \pm 0.05$ \\
Female & $0.32 \pm 0.05$ & $2.79 \pm 0.27$ & $0.21 \pm 0.03$ & $0.67 \pm 0.06$ & $0.81 \pm 0.06$ & $0.24 \pm 0.04$ \\
\hline
\end{tabular}

Table 2 Blood parameters of SD rats.

\begin{tabular}{lcccc}
\hline Parameter & Unit & Male $(n=7)$ & Female $(n=10)$ & Average $(n=17)$ \\
\hline RBC & $\times 10^{12} / 1$ & $8.12 \pm 0.77$ & $8.8 \pm 1.2$ & $8.6 \pm 1.1$ \\
HCT & $\mathrm{fl}$ & $0.429 \pm 0.046$ & $0.484 \pm 0.074$ & $0.462 \pm 0.068$ \\
MCV & $\mathrm{fl}$ & $52.8 \pm 2.5$ & $54.6 \pm 2.4$ & $53.9 \pm 2.6$ \\
RDW & $\mathrm{fl}$ & $10.5 \pm 0.7$ & $10.3 \pm 0.6$ & $10.4 \pm 0.6$ \\
WBC & $\times 10^{9} / 1$ & $12.0 \pm 2.9$ & $7.6 \pm 2.9$ & $9.4 \pm 3.6$ \\
LYM & $\%$ & $89.3 \pm 5.8$ & $93.6 \pm 3.0$ & $91.8 \pm 4.7$ \\
MON & $\%$ & $6.0 \pm 2.0$ & $1.9 \pm 1.3$ & $3.6 \pm 2.6$ \\
GRA & $\%$ & $1064 \pm 425$ & $1.9 \pm 1.3$ & $3.1 \pm 2.9$ \\
PLT & $7.2 \pm 2.9$ & $957 \pm 227$ & $1001 \pm 316$ \\
PCT & $\mathrm{fl} / 1$ & $6.8 \pm 0.3$ & $6.4 \pm 1.5$ & $6.7 \pm 2.1$ \\
MPV & $\mathrm{fl}$ & $32.7 \pm 2.5$ & $31.6 \pm 0.2$ & $6.7 \pm 0.2$ \\
PDW & $\mathrm{fl}$ & $129 \pm 12$ & $217 \pm 54$ & $32.1 \pm 1.8$ \\
Hb & $\mathrm{g} / 1$ & & $181 \pm 60$ \\
\hline
\end{tabular}

\section{DISCUSSION}

Several studies have reported on the toxicity of amygdalin $^{9,15,16}$. In this study we chose $2.25 \mathrm{mg}$ amygdalin/ml as a parameter of test substance. Results showed that this special wild apricot oil had no acute toxicity to SD rats of either sex. We had previously estimated an $\mathrm{LD}_{0}$ between $180 \mathrm{mg} / \mathrm{kg}$ bw or $514 \mathrm{mg} / \mathrm{kg}$ bw amygdalin ${ }^{12}$, and in this study, we chose test of maximum tolerated dose to evaluate the acute toxicity of mixture of refined wild apricot oil and added amygdalin. The dosage was equivalent to $36 \mathrm{mg} / \mathrm{kg}$ bw.

The rats obtained similar value on haematological parameters with normal ones, such as $\mathrm{RBC}, \mathrm{Hb}, \mathrm{MCV}$, PLT, WBC, LYM, and MON as well as visceral organ coefficient ${ }^{13,17,18}$. Neither the organ relative weights nor the external macroscopic morphology were altered by wild apricot oil. Thus wild apricot oil with high level amygdalin had no acute toxicity to SD rats.

The test substance $(2.25 \mathrm{mg}$ amygdalin $/ \mathrm{ml}$ in refined apricot oil) was an equivalent dosage for rats of about 1347 times that of the refined oil or 23 times that of the crude oil ( $6.45 \mathrm{mg} \mathrm{HCN} / \mathrm{kg}$ ). Rats administered with the special refined apricot oil did not show any kind of abnormal behaviour, during initial $1 \mathrm{~h}$ after drug administration. No mortality was observed during 17 days in male rats or 15 days in female rats after treatment. Refined wild apricot oil may be safer than the test substance. According to MOHC standards, the refined wild apricot oil is an innoxious substance ${ }^{8}$.

Digested bitter apricot oil had no toxicity to Wistar rats for a 13 -week feeding study ${ }^{19}$. Compared to digested bitter apricot oil, the refined wild apricot oil has a small amount cyanide. A further subacute toxicity study with refined oil may take for its safety evaluation.

Acknowledgements: We are thankful to Gaobo Zhang and Shuangfeng Zhang for their generous technical assistance with the feed and anatomy of the rats, and Mingzhe Fu for his work in blood routine examination. This study was supported by a grant from the research and development of deep processing technology of kernel-apricot, PR China (Special Research Programme for Public-welfare Forestry of the Chinese State Forestry Administration No. 200904020). The work completed in the Key Laboratory of Environment and Ecology in Western China, Ministry of Education.

\section{REFERENCES}

1. Rajaram MR, Kumbhar BK, Singh A, Lohani UC, Shahi NC (2012) Optimization of parameters for enhanced oil recovery from enzyme treated wild apricot kernels. J Food Sci Tech 49, 482-8.

2. Zhao YY (2012) Amygdalin content in four stone fruit species at different developmental stages. Sci Asia 38, 218-22.

3. Wang L, Yu H (2012) Biodiesel from Siberian apricot (Prunus sibirica L.) seed kernel oil. Bioresour Tech 112, 355-8. 
4. Bisht TS, Sharma SK, Sati RC, Rao VK, Yadav VK, Dixit AK, Sharma AK, Chopra CS (2013) Improvement of efficiency of oil extraction from wild apricot kernels by using enzymes. J Food Sci Tech, in press.

5. Gómez E, Burgos L, Soriano C, Marín J (1998) Amygdalin content in the seeds of several apricot cultivars. J Sci Food Agr 77, 184-6.

6. Barceloux DG (2009) Cyanogenic foods (cassava, fruit kernels, and cycad seeds). Dis Mon 55, 336-52.

7. Wang Z, Zhao Z, Zhu H (2010) Evaluation of uncertainty of cyanide in bitter almond oil by isonicotinic acid-barbituric acid spectrophotometry. Acta Agr Boreal Occident Sin 19, 174-7. (in Chinese).

8. Ministry of Health of the People's Republic of China (2003) GB 15193.3-2003: Acute Toxicity Test.

9. Adewusi SRA, Oke OL (1985) On the metabolism of amygdalin. 1. The $\mathrm{LD}_{50}$ and biochemical changes in rats. Can J Physiol Pharmacol 63, 1080-3.

10. Hussain T, Fareed S, Siddiqui HH, Vijaykumar M, Rao CV (2012) Acute and subacute oral toxicity evaluation of Tephrosia purpurea extract in rodents. Asian Pac J Trop Dis 2, 129-32.

11. Liu D, Geng T, Zhang L, Yao W, Ding A, Shan M (2012) Acute and subacute toxicity and genotoxicity of schizonepetin, a naturally occurring monoterpene with antiviral activity. Food Chem Toxicol 50, 2256-62.

12. Li X, Luo Y, Wang L, Li Y, Shi Y, Cui Y, Xue M (2010) Acute and subacute toxicity of ethanol extracts from Salvia przewalskii Maxim in rodents. J Ethnopharmacol 131, 110-5.

13. Costa-Silva J, Lima CR, Silva EJR, Araújo AV, Fraga MCCA, Ribeiro e Ribeiro A, Arruda AC, Lafayette SSL, Wanderley AG (2008) Acute and subacute toxicity of the Carapa guianensis Aublet (Meliaceae) seed oil. J Ethnopharmacol 116, 495-500.

14. Alam M, Galav V (2013) Subacute 28 days repeated toxicity assessment of thymoquinone (volatile oil of black seed) in wistar rats. Indian J Sci Res 4, 75-9.

15. Newton GW, Schmidt ES, Lewis JP, Conn E, Lawrence $\mathrm{R}$ (1981) Amygdalin toxicity studies in rats predict chronic cyanide poisoning in humans. West J Med 134, 97-103.

16. Adewusi SRA, Oke OL (1985) On the metabolism of amygdalin. 2. The distribution of $\beta$-glucosidase activity and orally administered amygdalin in rats. Can J Physiol Pharmacol 63, 1084-7.

17. Fan X, Deng H, Zhang L (2009) Toxicological assessment of the edible safety of cold-pressed Xanthoceras sorbifolia bunge seed oil. China Oils Fats 34 (5), 32-7. (in Chinese).

18. Huang F, Xie B, Niu Y (2006) A toxicological research on food safety of Camelina sativa oil. J Chin Cereals Oils Assoc 21 (5), 102-8. (in Chinese).

19. Gandhi VM, Mulky MJ, Mukerji B, Iyer VJ, Cherian KM (1997) Safety evaluation of wild apricot oil. Food Chem Toxicol 35, 583-7. 